\title{
Comunidade Remanescente de Quilombo, desigualdade e política pública: reflexões sobre um 'caso particular do possível' das mulheres quilombolas em uma comunidade na região norte-rio-grandense
}

\author{
Remaining Community of Quilombo, inequality and public policy: reflections
} on a quilombolas women 'particular case of the possible' in a community in the norte-rio-grandense region

\section{Comunidad Remanescente de Quilombo, desigualdad y política pública: reflexiones sobre un 'caso particular del posible' de las mujeres quilombolas en una comunidad en la región norte-rio-grandense}

\author{
Marcela Fernanda da Paz de Souza ${ }^{1}$ \\ Wagner Luiz Alves da Silva ${ }^{2}$ \\ Luzimar Pereira da Costa ${ }^{3}$
}

Recebido em 02/07/2018; revisado e aprovado em 14/04/2019; aceito em 14/04/2019

DOI: http://dx.doi.org/10.20435/inter.v20i4.2033

\begin{abstract}
Resumo: As Comunidades Remanescentes de Quilombo permanecem, em sua maioria, com altas taxas de desigualdade, com a submissão das mulheres às distintas formas de opressão. Demarca-se como campo de estudo, a Comunidade Quilombola Negros do Riacho. O desenho da pesquisa abrange a revisão bibliográfica, o mapeamento socioambiental do território e a aplicação de questionário. O resultado indica a ausência da atuação governamental, do investimento público e uma restrita capacidade reivindicatória da associação comunitária.
\end{abstract}

Palavras-chaves: quilombo; desigualdade; mulher.

Abstract: Most of the Remaining Communities of Quilombo still suffer from high rates of inequality and women's submission to different forms of oppression. The Negros do Riacho Quilombola Community was demarcated as a field of study. The survey design covers the bibliographic review, the socio-environmental mapping of the territory and the application of a quiz. The result indicates the absence of governmental action, public investment and a limited bargaining power of the community association.

Keywords: quilombo; inequality; woman.

Resumen: Las comunidades remanentes de Quilombos permanecen, en su mayor parte, con altas tasas de desigualdad, además del sometimiento de las mujeres a distintas formas de opresión. La comunidad quilombola "Negros do Riacho" fue elegida en este estúdio. La investigación que proponemos presenta una revisión bibliográfica, una cartografía socioecológica del territorio y la aplicación de una encuesta. El resultado indica la ausencia de acción gubernamental, inversión pública y un poder de negociación restrictivo de la asociación comunitaria.

Palabras clave: quilombo; desigualdad; mujer.

\footnotetext{
${ }^{1}$ Universidade do Estado de Minas Gerais (UEMG), Frutal, Minas Gerais, Brasil.

${ }^{2}$ Instituto Federal de Educação, Ciência e Tecnologia do Rio Grande do Norte (IFRN), Natal, Rio Grande do Norte, Brasil.

${ }^{3}$ Secretaria de Estado da Educação do Rio Grande do Norte, Natal, Rio Grande do Norte, Brasil.
} 


\section{COMUNIDADES REMANESCENTES DE QUILOMBO: ENFRENTANDO OS DESAFIOS DA DESIGUALDADE}

As comunidades remanescentes de quilombos são caracterizadas como um grupo étnico pertencente aos povos e às comunidades tradicionais (CARTILHA DE POVOS E COMUNIDADES TRADICIONAIS, 2013), compreendendo-se o significado básico do termo "étnico" na sua acepção contemporânea "no sentido que descreve um grupo possuidor de algum grau de coerência e solidariedade, composto por pessoas conscientes, ao menos de forma latente, de terem origens e interesses comuns" (CASHMORE, 2000, p. 196).

O quilombo, organização social de tipo específico e de caráter étnico (LEITE, 2000), é compreendido, em seu conceito moderno, como formado por povos remanescentes de quilombo, coadunado aos conceitos de identidade étnica e territorialidade (SCHMITT; TURATTI; CARVALHO, 2002).

A territorialidade também pode ser compreendida como a representação dos possíveis tipos de usos de um determinado território (FERNANDES, 2008). A regulamentação da titulação das terras das comunidades remanescentes de quilombo consta no Art. 68 do Ato das Disposições Constitucionais Transitórias (ADCT/68): "Aos remanescentes das comunidades dos quilombos que estejam ocupando suas terras é reconhecida a propriedade definitiva, devendo o Estado emitir-lhes os títulos respectivos".

À luz do art. 68, O’Dwyer (2002) demonstra a necessidade de que os atores estabeleçam uma relação de correspondência entre a invocação do passado a uma existência contemporânea relacional que inclua a determinação do universo social com outros grupos, comunidades e sociedades conformativas que não aquelas dos povos e das comunidades tradicionais quilombolas.

Por se tratar de um povo historicamente excluído, que enfrenta desigualdades e barreiras para a vivência plena de sua materialidade e cultura, a identidade quilombola traduz uma possibilidade emancipatória para essas populações (SCHMITT; TURATTI; CARVALHO, 2002).

No âmbito das políticas públicas para as comunidades remanescentes de quilombo, criou-se o Programa Brasil Quilombola (PBQ) no ano de 2004 e, com o seu desenvolvimento, a Agenda Social Quilombola (ASQ), com o Decreto n. 6.261/2007. A prerrogativa do PBQ é consolidar as ações do Estado para as comunidades quilombolas (GUIA PROGRAMA BRASIL QUILOMBOLA, 2013; BRASIL, 2007).

É importante salientar que o PBQ e o ASQ constituem políticas que indicam uma mudança de um padrão de políticas de caráter cultural para a ação governamental na abrangência setorial das políticas públicas (ARRUTI, 2009). Para as ações do PQB se tornarem efetivas na transversalidade que lhe são próprias, a gestão ocorre de forma descentralizada, com a coordenação geral da Secretaria de Políticas de Promoção da Igualdade Racial (SEPPIR/PR), conjuntamente com ministérios públicos, governos estaduais e municipais, movimentos e organismos não governamentais e secretarias de políticas de igualdade racial (PIR) (PROGRAMA BRASIL QUILOMBOLA, 2016).

Em relação às políticas públicas específicas para as mulheres das comunidades quilombolas, estudos (SOUZA; ARAÚJO, 2014; SOUZA; ANTUNES; NUNES, 2013; SILVA; MENEZES-SANTOS, 2015) demonstram a invisibilidade desse grupo específico no desenho das políticas. Ainda que o reconhecimento étnico (LÉO NETO, 2012), as convenções internacionais para os povos e as comunidades tradicionais; a exigência normativa de associações comunitárias nas comunidades remanescentes de quilombos (BEZERRA, 2014) e os movimentos sociais específicos para essa 
população viabilizem uma ação feminina na luta e na reivindicação dos seus direitos, permanece acentuado o número de mulheres quilombolas em situação de pobreza e sem acesso às políticas específicas às suas reais necessidades.

\section{DESENHO DA PESQUISA}

Conforme os dados do Instituto Nacional de Colonização e Reforma Agrária (INCRA) e Fundação Cultural Palmares, com base de referência em dezembro de 2014, há 2.422 CRQs com registro oficialmente reconhecidos pelo Estado (PROGRAMA BRASIL QUILOMBOLA, 2016). As famílias estão distribuídas 77,7\% em área rural e 22,3\% em área urbana. É importante verificar a situação de extrema pobreza desse grupo étnico. Entre as 82.000 famílias inscritas no Cadúnico, aproximadamente $70,6 \%$ apresentavam renda familiar inferior a $\mathrm{R} \$ 77,00$. A baixa escolarização e o analfabetismo são outras realidades dessas comunidades. Aproximadamente, $24,81 \%$ não sabem ler. Em apenas 26,9\% há coleta de lixo. O escoamento sanitário ocorre em 9,9\% em vala a céu aberto e 59\% em fossa rudimentar (PROGRAMA BRASIL QUILOMBOLA, 2016).

Com o objetivo de verificar na prática da vida social (GIDDENS, 2005) a desigualdade das mulheres das comunidades remanescentes de quilombo, o eixo demarcado para a análise são as mulheres da Comunidade Remanescente de Quilombo Negros do Riacho. O Riacho dos Anginos está localizado na Zona Rural de Currais Novos, município integrante da Região do Seridó Norterio-grandense, a $180 \mathrm{~km}$ de Natal, capital do RN. A Comunidade foi retratada em outros estudos (ANDRADE FILHO et al., 2011; OLIVEIRA, 2012) como o quilombo mais pobre do RN, com pedintes, com casos de anemia falciforme (dados da pesquisa, 2015; OLIVEIRA, 2012), saneamento básico precário e de mau trato relacionado ao uso do território como, por exemplo, o excesso de lixo espalhado (dados da pesquisa, 2015).

O desenho da pesquisa foi realizado a partir da revisão bibliográfica, do mapeamento socioambiental do território e da aplicação de um survey semiestruturado. Empreendeu-se o trabalho de campo nos meses de outubro e de dezembro de 2015. A equipe dos pesquisadores contou com a colaboração do presidente da associação comunitária, José da Silva Oliveira, e de um morador para a demarcação das dimensões reais da comunidade para a construção do mapa.

O questionário contém 66 perguntas, entre as questões objetivas e abertas de percepção das respondentes. Entrevistou-se um total de 36 mulheres, com 32 questionários válidos. As demais mulheres não estavam em casa ou não quiseram responder. Como critério para a escolha das entrevistadas, delimitou-se uma participante por casa que dividisse a responsabilidade pelo domicílio, com o cônjuge ou outro familiar, ou que pelo menos já possuísse um filho.

Em razão das delimitações do espaço, não foi possível englobar na análise todos os resultados encontrados no estudo. Os blocos estruturantes do survey apresentam o seguinte critério: a) Caracterização de atributos individuais, educacionais e profissionais; escolaridade e faixa etária dos filhos; organização social e vida associativa e religiosa; b) Rendimento e programas sociais: trabalho, outros rendimentos; programas sociais; c) Agricultura familiar; d) Produção de cerâmica; e) Papel na família; f) Vida no quilombo: individual, familiar e comunitária; g) Moradia; h) Acesso às tecnologias da informação e comunicação.

Espera-se com o 'caso particular do possível' (BOURDIEU, 1996) contribuir para a ampliação das informações sistematizadas referente às desigualdades que perpassam as comunidades remanescentes de quilombo; viabilizar a análise de dados diante do desafio da integração e da 
qualidade da informação disponibilizados para os gestores públicos, movimentos e organizações não-governamentais; ampliar as chaves interpretativas da relação entre territorialidade, desigualdade e gênero.

\section{CONHECENDO OS NEGROS DO RIACHO...}

A figura mítica, simbolizada pelas "significações imaginárias sociais" e representada na memória e na ação coletivas (POUTIGNAT; STREIFF-FENART, 1998), encarna, em Trajano Lopes da Silva ou Trajano Passarinho, a cepa que se ramificou na Comunidade Quilombola Negros do Riacho (figura 1), município de Currais Novos, na Microrregião Geográfica do Seridó Oriental, em terras potiguares, em meados do século XIX, e que iniciou a formação da comunidade remanescente dos quilombos "Sítio Bom Sucesso", "Riacho dos Anginos" ou os "Negros do Riacho" (SILVA, 2009; ANDRADE FILHO et al., 2011).

O período da ocupação do território até os dias atuais não ocorreu sem conflitos (SILVA, 2009; ANDRADE FILHO et al., 2011). As considerações de Medeiros (2008) sobre território e identidade podem ser verificadas, também, nesse caso específico da descendência de Trajano, em relação ao quilombo. A formação territorial se processa no compartilhamento de significados e de pertencimento ao local onde é forjada a identificação para, posteriormente, tornar-se um espaço constitutivo de relações de poder. Aqui, na demarcação territorial, os jogos políticos e a delimitação fronteiriça implicam controle (MEDEIROS, 2008).

Se, por um lado, os territórios quilombolas são produtos de conflitos (FERNANDES, 2008), por outro, seus arranjos internos não ocorrem sem dissensões. Um exemplo é na demarcação simbólica e territorial entre a "raça dos negros" e a "raça dos caboclos" na Comunidade.

Os "filhos" de Trajano Passarinho obtiveram a certidão da Fundação Palmares em 2006. As informações do líder comunitário da Associação Comunitária de Desenvolvimento Negros do Riacho, José da Silva Oliveira, é que há, hoje, no quilombo, 47 casas, totalizando 280 moradores, aproximadamente uma média de seis pessoas por habitação. A Comunidade está localizada a uma distância de $9 \mathrm{~km}$ de Currais Novos e a $6 \mathrm{~km}$ da BR 226. As informações colhidas junto às entrevistadas indicaram que, em todas as casas, há energia elétrica e água encanada proveniente de um 'poço'. Sobre o escoamento sanitário, há duas situações: as águas da pia e das torneiras são em valas a céu aberto e a do banheiro, em fossas rudimentares, também conhecidas por fossas negras (dados da pesquisa, 2015). 
Figura 1 - Comunidade Quilombola Negros do Riacho - Currais Novos, RN

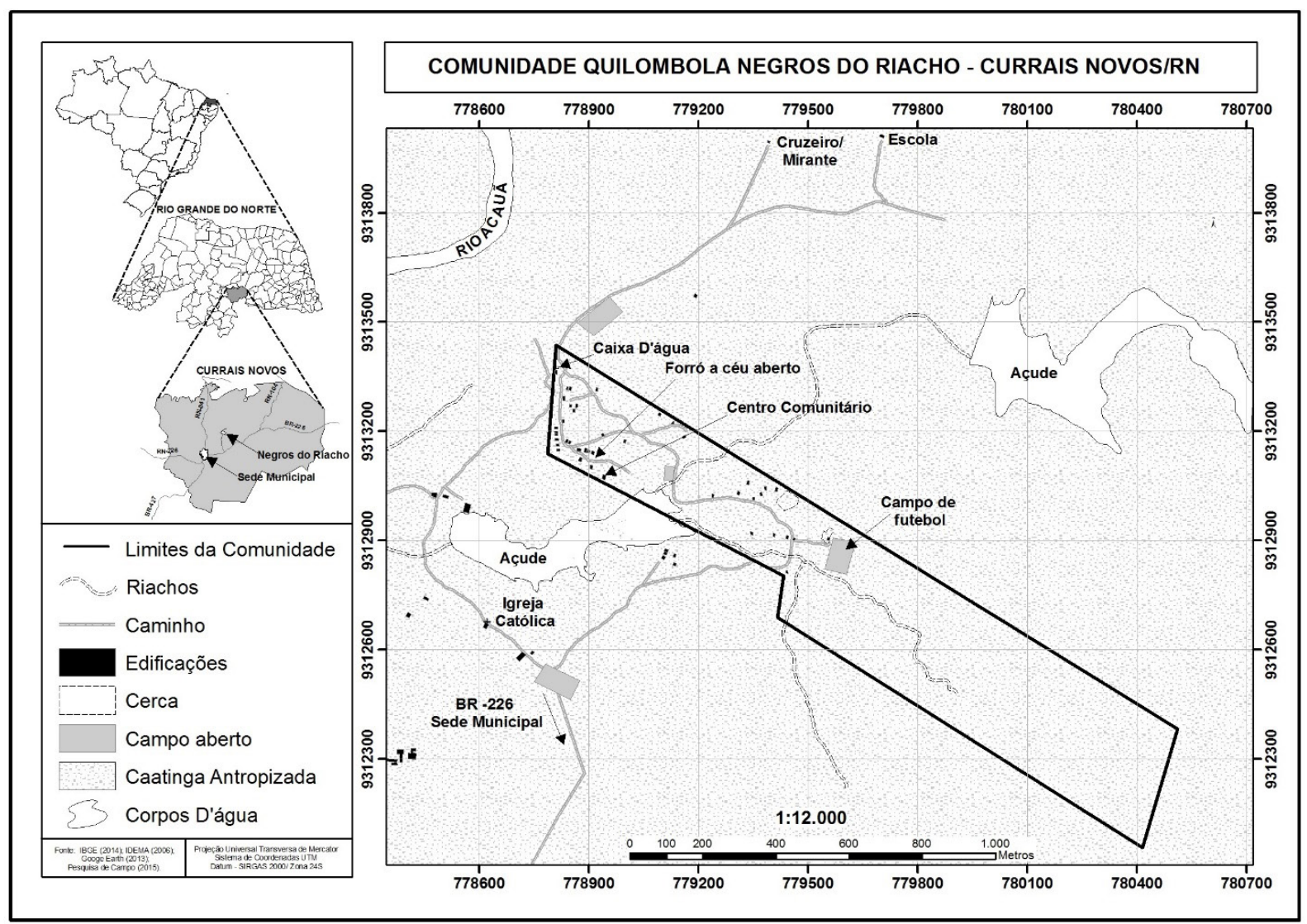

Fonte: Instituto Brasileiro de Geografia e Estatística (IBGE, 2014); Instituto de Defesa do Meio Ambiente (2006); Google Earth (2013); Pesquisa de Campo (2015).

O Breve Diagnóstico Situacional da Comunidade "Negros do Riacho" (ANDRADE FILHO et al., 2011) aponta essa comunidade remanescente do quilombo como a mais pobre do Estado do Rio Grande do Norte. O Diagnóstico e outros estudos (SILVA, 2009; OLIVEIRA, 2012) sobre o Riacho relataram uma situação de pedição, constatada, também, pela equipe de pesquisadores.

Alguns moradores (um deles já na terceira idade) pediram dinheiro ou "qualquer outra coisa". Conforme a observação da equipe nas vezes em que visitou o 'Riacho', esta é uma prática comum entre muitos membros da comunidade. As dificuldades financeiras também são apontadas pelos relatos levantados em campo, pois o tamanho da comunidade era maior, mas alguns moradores venderam as suas propriedades por pequenas quantias financeiras (pesquisa de campo, 2015).

O desenho das políticas para as comunidades quilombolas prescinde, portanto, da produção territorial dessas terras de preto. É importante observar a contribuição de Raffestin (2008) para quem "a produção territorial, neste sentido, é um processo complexo que devemos aprender a descrever e a entender para reproduzi-lo ou modificá-lo através do planejamento territorial" (RAFFESTIN, 2008, p. 26).

Conforme indicado no mapa, há parcialmente um açude particular na área da Comunidade Negros do Riacho. Nas imagens de satélite utilizadas para a construção do mapa e a visita de campo, verificou-se que o açude, naquele momento, tratava-se de um reservatório seco de pequena proporção. Possivelmente o açude encontrava-se seco em decorrência dos riachos que 
o alimentam serem intermitentes e do severo período de seca (se uniriam e desaguariam no Rio Acauã). Conforme relatos de moradores do quilombo, quando está cheio, o reservatório é utilizado pela Comunidade.

Uma das necessidades apontadas pelos membros da comunidade e por uma entrevistada durante a aplicação dos questionários é a necessidade de um açude próprio do quilombo. O investimento público, nesse sentido, é fundamental, em razão de a obra de um açude, no quilombo, poder atender à irrigação da agricultura familiar, à medida que a região é penalizada pela escassez de chuva, e à dessedentação dos animais criados por parte dos moradores do quilombo. Nesse sentido, verifica-se a importância dos usos e dos significados de determinado grupo ou população ao seu território (MEDEIROS, 2008).

Verificou-se, nas visitas ao campo, o mau trato com o quilombo, com lixo espalhado em diversos pontos da comunidade. Os dados da pesquisa indicaram que apenas $9 \%$ das mulheres entrevistadas realizam prática de proteção ao meio ambiente. E, de acordo com a informação das respondentes, as ações se referem à coleta seletiva (dados da pesquisa, 2015).

A falta de cuidado com a estrutura física da comunidade, por parte de seus próprios membros, prescinde da reflexão de Fernandes (2008), cujo argumento é sobre a relação entre sujeito-território: os sujeitos constroem seus territórios e, se há sua destruição, ocorre o fim dos sujeitos e dos grupos.

\section{MULHERES QUILOMBOLAS: PERFIL SOCIOECONÔMICO E PRÁTICAS PRODUTIVAS TRADICIONAIS}

A composição étnica na formação da Comunidade Quilombola Negros do Riacho situa a reflexão em duas direções. A primeira está relacionada às observações de O'Dwyer sobre a construção das fronteiras étnicas que demarcam as comunidades rurais negras e a sua continuidade na delimitação desses grupos. Nesse caso, é possível "considerar que a afiliação étnica é tanto uma questão de origem comum como de orientação das ações coletivas no sentido de destinos compartilhados" (O'DWYER, 2007, p. 45-6). A segunda direção é que, entre as mulheres entrevistadas, a identificação como 'cabocla' ou 'negra' não é mais tão determinante como apontado nos estudos anteriores (ASSUNÇÃO, 1994; NEGREIROS; 2001), o que constituía uma divisão simbólica e/ou material, como Fernandes (2008) indica a construção de "territórios dentro de território".

É importante considerar que, embora haja uma 'divisão' entre os negros e os caboclos, entre as $78,1 \%$ das respondentes autodenominadas caboclas, ao serem questionadas sobre se "sentiam orgulho em serem caboclas" e o "porquê", apenas em dois casos responderam sentir orgulho; a metade não respondeu; e as demais disseram não se importar por serem ou não da "raça cabocla".

Pesquisas sobre as atividades laborais das mulheres das comunidades rurais demonstram a dificuldade em se estabelecer a separação precisa entre espaço doméstico e espaço produtivo (SCOTT; RODRIGUES; SARAIVA, 2010; MONTEIRO, 2013). Entretanto, neste ponto específico da reflexão, apontou-se o percentual das mulheres donas de casa com o objetivo de verificar quais realizavam os cuidados com a casa e com os filhos (GIDDENS, 2005) excluindo as atividades relacionadas às práticas econômicas familiares ou extra-lar remuneradas, resultado que alcançou 90,6\%.

Dialogando com pesquisas (PARÉ; OLIVEIRA; VELOSO, 2007; ARRUTI, 2009) sobre os desafios de ordem educacional das comunidades e das mulheres quilombolas, verificaram-se a baixa 
escolaridade e o analfabetismo das entrevistadas. Todas as mulheres analfabetas, $21,9 \%$, são negras; aproximadamente $31 \%$ das mulheres estudaram o ensino fundamental sem, entretanto, chegarem a concluir (dados da pesquisa, 2015).

É relevante observar a carência de informação de algumas das mulheres sobre a vida dos filhos. Entre as entrevistadas, $46 \%$ possuem seis ou mais filhos, com o percentual da primeira gravidez em torno de 13 e 14 anos. Duas respondentes de 16 anos já são mães, com gestação também aos 14 anos. Verificou-se, na pesquisa, a dúvida ou o não conhecimento das respondentes em relação à idade e à escolaridade dos filhos. Este é um dos grandes desafios que contribui para a reprodução das condições de desigualdade desse grupo.

\section{RENDIMENTO E PRÁTICAS PRODUTIVAS TRADICIONAIS}

O rendimento individual e familiar declarado pelas entrevistas é proveniente, em 75\% dos casos, especialmente do PBF. As demais respondentes, 25\%, não recebem o PBF. A renda individual declarada pelas mulheres beneficiárias se refere, na maior parte dos casos, unicamente ao benefício do PBF recebido. Uma respondente contribui para a previdência, e duas são aposentadas. Os rendimentos das mulheres que se dedicam à prática do artesanato ou da agricultura não foram todos declarados, mas duas aposentadas recebem, com a atividade, cerca de $R \$ 500,00$ e, outra artesã, $R \$ 250,00$.

O território em sua dimensão de espaço de vida, de propriedade privada e comunitária, implica distintos usos, como por exemplo, para práticas produtivas de subsistência ou alimentação, que podem ser observados nas comunidades quilombolas (FERNANDES, 2008).

A agricultura familiar constitui uma das tipificações que caracterizam a identidade camponesa quilombola (FIDELIS; BERGAMASCO, 2013). Alguns dos fatores constitutivos da agricultura tradicional na prática campesina e encontrados também nas comunidades quilombolas se referem à utilização da terra, com técnicas e conhecimento das práticas agrícolas, por meio da experiência familiar e da transmissão geracional e informal dos saberes. É estabelecida uma reciprocidade entre a cultura de uma comunidade específica e a maneira como este grupo desenvolve o cultivo (REMMERS, 1993).

Conforme os dados da pesquisa (2015), a base econômica e de subsistência é a agricultura familiar, especialmente nos períodos de chuva, notadamente a pequena fruticultura e a pecuária (gado bovino, caprino e ovino).

A plantação é, em sua maioria, de milho, feijão e jerimum. Conforme as respondentes, $11 \%$ das mulheres, vendem sua produção para Currais Novos.

Entre as mulheres entrevistadas, $30 \%$ se dedicam à atividade da agricultura familiar. $\mathrm{E}$, entre estas, $67 \%$ cultivam com o marido. Como as plantações ocorrem, especialmente, no período das chuvas, o percentual de pessoas que trabalham com esta atividade possivelmente é maior.

Na agricultura familiar das mulheres Negras do Riacho, a prática da plantação foi ensinada pelos pais e essas mulheres aprenderam as "técnicas" observando seus familiares na lida (dados da pesquisa, 2015).

Cerca de 19\% das mulheres exercem atividades relacionadas à produção de panelas, pratos e jarros de cerâmica, trabalham da extração da matéria-prima para a produção das peças e auxiliam na comercialização em Lagoas Novas, Natal ou na própria casa. Desse grupo que se dedica ao artesanato, $17 \%$ desenvolvem as atividades com os filhos, e $17 \%$, com os pais. Um total de 
83\% declarou que o sustento é a principal importância de desenvolverem os artesanatos, e 17\% considera a prática relevante principal para a manutenção da tradição.

Como o limiar das atividades domésticas e produtivas é muito tênue entre as mulheres rurais (SCOTT; RODRIGUES; SARAIVA, 2010; MONTEIRO, 2013), verificou-se que, embora 9,4\% tenham declarado como profissão 'artesãs do barro', outras respondentes, 10\%, desenvolvem atividades de produção familiar de cerâmica. E, ainda, 30\% das entrevistadas se dedicam à agricultura familiar. Duas respondentes se dedicam a ambas as atividades (dados da pesquisa, 2015).

A produção da cerâmica é tradição entre as comunidades quilombolas (MONTEIRO, 2013). Com exceção de uma entrevistada que aprendeu o ofício com a sogra, as demais declararam que a iniciação ao artesanato ocorreu por meio do conhecimento transmitido geracionalmente pelos pais e que as técnicas foram aprendidas através da observação.

Haja vista o papel da agricultura familiar e da cerâmica para o fortalecimento e a valorização étnico-identitária das CRQ's, as mulheres entrevistadas responderam que não são beneficiadas e que nem participaram de quaisquer programas de incentivo a essas atividades produtivas tradicionais. Na dimensão analítica sobre as mulheres rurais realizada por Hernández (2010)- capaz de elucidar o olhar sobre o grupo de Trajano Passarinho- é importante observar as matizes que substanciam as assimetrias e as relações de poder entre os sexos.

Entre os aspectos basilares da desigualdade, estão as "responsabilidades das mulheres tanto na esfera doméstica quanto no trabalho produtivo (em atividades agropecuárias) e reprodutivo, as quais marcam a sua contribuição, embora nem sempre reconhecida nem remunerada na agricultura familiar" (HERNÁNDEZ, 2010, p.103).

\section{CONDIÇÕES DE VIDA, POLÍTICAS PÚBLICAS E ORGANIZAÇÃO POLÍTICA: OUTRAS DIMENSÕES CONFORMATIVAS DA DESIGUALDADE DAS ‘FILHAS DE TRAJANO’}

Contribuindo com a reflexão para a compreensão das desigualdades da população afro-brasileira, Lima ressalta o papel da identidade étnico-racial e seu impacto na distribuição assimétrica de bens e recursos, em uma dignidade aviltada, que "mantém a maioria dessa população entre os pobres, miseráveis, subempregados, analfabetos e despossuídos em geral" (LIMA, 2008, p. 41).

As mulheres quilombolas apresentam um quadro de desigualdade e discriminação, cujo caráter interseccional viabiliza uma subordinação, ao mesmo tempo, de gênero, classe, etnia, classe, idade, entre outros atributos socialmente demarcados (SOUZA; ARAÚJO, 2014).

Com o objetivo de conhecer essa realidade entre as participantes da pesquisa, questionou-se às entrevistadas sobre a percepção que possuem da vida no quilombo e sobre a opinião que elas possuem relativa ao preconceito.

Apesar da acentuada vulnerabilidade constatada na pesquisa, um percentual de 93,5\% se orgulha em pertencer ao quilombo. O vínculo de pertencimento, de morar em uma comunidade que lhes dê uma dimensão de segurança (36\%) e de tranquilidade (36\%) são dois atributos indicados pelas mulheres e que denotam a valorização dessas mulheres à comunidade.

A cor, o estranhamento em relação ao modo de vida, a própria concepção da população da região de que os negros do riacho são preguiçosos (SILVA, 2009) estão entre as maiores ocorrências de percepção das mulheres quilombolas relacionadas ao preconceito (dados da pesquisa, 2015).

Verificaram-se, ainda, junto às quilombolas, quais as melhorias que elas desejam para si próprias, para os membros da família e para a comunidade. Torna-se possível observar os 
principais gaps de acesso aos recursos promotores do bem-estar, tanto na experiência subjetiva, quanto na avaliação das respondentes sobre as condições sociais dos familiares e, de uma forma geral, do Rancho.

Constatou-se que uma das principais reivindicações das mulheres entrevistadas se relaciona aos cuidados com a saúde. O relato de algumas entrevistadas é que o atendimento médico é feito em um espaço improvisado (em uma casa), e possibilita aos moradores terem acesso às informações compartilhadas durante a consulta: todos ficam sabendo quando alguém está doente e qual doença tem.

Esse resultado reporta às causas sociais da desigualdade de saúde, cujo caráter explicativo perpassa os ativos econômicos, mas também nas redes sociais estabelecidas em termos de poder, prestígio, conhecimento e acesso às informações que se coadunem com o bem-estar e a capacidade de prevenção (LINK; PHELAN, 1995; FIGUEIREDO SANTOS, 2011).

As condições de acesso à saúde na comunidade são precárias (dados da pesquisa, 2015). Em pesquisa anterior, como Oliveira (2012), foi relatada a incidência de anemia falciforme entre os Negros do Riacho. Esse tipo de anemia é grave, incurável e com alta taxa de morbimortalidade. A declaração da Casa de Apoio à Criança com Câncer Durval Paiva entregue para a pesquisa, datada de 18 de junho de 2012, demonstrou que havia, naquele momento, três crianças acolhidas com anemia falciforme e que, no núcleo familiar, outras pessoas eram portadoras da doença. Por haver uma prevalência de um para cada 380 nascidos vivos, da doença, que é genética e que afeta, nas Américas, os afrodescendentes (AAFESP, 2016), percebe-se que a situação é delicada na Comunidade. Outro aspecto ressaltado por Oliveira é que não ocorria um acompanhamento especializado na comunidade, o que dificultava a verificação do impacto da doença e das pessoas com os traços deste tipo de anemia.

A verificação dos dados da pesquisa indicou que, entre as mulheres quilombolas entrevistadas, $18 \%$ desejam melhoria na própria saúde; $15,6 \%$, na saúde da família, e $87,5 \%$, declararam a importância de um posto de saúde dentro da comunidade.

A restrição de acesso aos recursos de saúde da Comunidade Negros do Riacho pode ser observada em uma abordagem da estrutura dos Determinantes Sociais das Desigualdades em Saúde (Commission on Social Determinants of Health [CSDH]). O modelo do CSDH define como determinantes estruturais o contexto socioeconômico e político; a hierarquia social - classe, prestígio, honra e discriminação, poder e recursos; posição socioeconômica- renda, educação, ocupação, gênero, etnicidade e educação. Os efeitos dos determinantes estruturais implicam a distribuição assimétrica de recursos e de acesso à saúde e configuram os determinantes sociais das desigualdades em saúde (CSDH, 2007).

Um segundo problema no quilombo, apresentado pelas respondentes, é a condição de desemprego. Um total de 59,4\% declarou que precisa de emprego para elas, 53,2\%, para a família e, 9,4\%, para a comunidade. Concomitantes a essas informações, é importante ressaltar que $12,5 \%$ mulheres declararam a necessidade de estudo para si, 21,9\% para a família, 18,8\%, ressaltaram o desejo que no quilombo se tenha uma escola, e 6,3\%, uma creche. Conforme os relatos de respondentes, algumas moradoras estão conseguindo emprego, o que sempre foi difícil, em razão do 'preconceito', ou seja, da prática, da discriminação.

Entende-se por reservas de oportunidades as vantagens de acesso de indivíduos ou grupos a recursos em uma interdependência relacional com as desvantagens que os demais indivíduos ou grupos possuem no acesso a esses mesmos recursos (WRIGHT, 2008). Retomando as observações 
de Dias (2013, p. 214), "há padrões de exclusão que podem ser considerados extremamente radicais, em que o preconceito e a discriminação tornam-se altamente organizados e focados".

\subsection{Políticas Públicas}

A situação de vulnerabilidade e de invisibilidade está inscrita em boa parte das comunidades tradicionais (CARTILHA..., 2013).

Retomando o PBQ, é importante situá-lo, em conjunto com o ASQ, no rol de públicas políticas para as $C R Q$ s e que significam uma mudança de padrão de gestão do Estado em relação aos grupos quilombolas. Para as ações do PQB se tornarem efetivas na transversalidade que lhe são próprias, a gestão ocorre de forma descentralizada, com a coordenação geral da Secretaria de Políticas de Promoção da Igualdade Racial (SEPPIR, PR), conjuntamente com ministérios públicos, governos estaduais e municipais, movimentos e organismos não governamentais e secretarias de políticas de igualdade racial (PIR) (GUIA..., 2013).

Verificou-se junto às entrevistadas quais são os programas sociais que as assistem ou já as beneficiaram no eixo 4- Direitos e Cidadania: promoção e garantia de direitos, a participação social dos representantes das comunidades na esfera pública e nos processos decisórios e de controle no Programa Brasil Quilombola (PBQ), e nos programas com objetivos afins a este de iniciativa estadual ou municipal.

São os programas: Programa Bolsa Família; Pronaf; Pronaf Mulher; Programa Bolsa Verde; Outro programa financeiro para produção rural; Programa financeiro de incentivo à produção cultural de cerâmica; Programa financeiro de incentivo a qualquer outro produto cultural; É beneficiário de algum programa de incentivo à comercialização de cerâmica ou outro bem cultural produzido no quilombo; Participação da respondente ou de algum outro familiar no Pronatec; Escola do campo- escola quilombola; Programa Procampo - Saberes da Terra.

Conforme as respondentes, com exceção do PBF, elas não participam de nenhum dos outros programas sociais. É importante o benefício para a retirada da situação de extrema vulnerabilidade, o que ficou provado pela eficiência e efetividade do PBF, mas deve-se oferecer e estimular os instrumentos de qualificação profissional para que essas mulheres permaneçam na nova situação econômica e social de forma independente, gerando consumo e mais renda, sendo capaz de criar seus filhos e ter uma vida digna sem programas de transferência de renda. Além disso, é importante que essa mulher se sinta incentivada a participar dos cursos ofertados.

Deve-se ressaltar os desafios de implementação das políticas, como por exemplo, a sistematização dos dados oficiais das CRQs, com qualidade de informação e potencialidade de acesso integrado para um efetivo processo intersetorial e transversal dos programas e ações (ENAP, 2014). Outra dificuldade é a execução orçamentária do PBQ, o qual não alcançou as cifras inicialmente propostas. Há, ainda, as políticas para muitos grupos minoritários como os quilombolas, cujo reconhecimento não implica necessariamente políticas diferenciadas (ARRUTI, 2009).

\subsection{Associação Comunitária}

As associações comunitárias das CRQs são uma exigência normativa da ADCT/art.68 que as situam como uma exigência para a titulação das terras (SHIRAISHI NETO, 2014). A sede da Associação Comunitária de Desenvolvimento Negros do Riacho foi construída em 1994, com a ajuda de religiosos alemães. Em 2005, a Prefeitura Municipal de Currais Novos restaurou a obra, 
e no dia 4 de setembro daquele ano se instituiu a Associação (dados da pesquisa, 2015; SILVA, 2009; ANDRADE FILHO et al., 2011).

Nesses anos de atuação, a Associação realizou trabalhos bem básicos, como captar apoio junto ao poder público local, como a estrada de terra que está em melhores em condições, com os buracos e desníveis aplainados pelo trator (dados da pesquisa, 2015).

A pesquisa constatou a participação de $43,8 \%$ das mulheres na associação comunitária. A frequência semanal nas reuniões da associação é de $14,3 \%$ e, mensal, 57,2\%. Sobre as atividades que as entrevistadas exercem na comunidade, $78,7 \%$ responderam serem apenas ouvintes, e 7,1\% atuam como artesãs.

Ao se observar a relação entre a participação na associação e a escolaridade, verifica-se o percentual de analfabetas, de quem nunca estudou e escolaridade de até apenas a 5o série do Ensino Fundamental. Embora, conforme Souza, a "comunidade tem na dimensão político-organizativa uma força central que dinamiza e oxigena essa luta como coletiva das comunidades pela garantia de seus direitos" (SOUZA, 2002, p. 7), na comunidade pesquisada, a participação política das mulheres, para ser efetiva e emancipatória, necessita de uma formação educacional que, ao menos, as permita exercer com qualidade e reconhecimento o seu estatuto do sujeito político (CHAGAS, 2001).

\section{CONSIDERAÇÕES FINAIS}

A desigualdade a que as mulheres da Comunidade Negros do Riacho estão submetidas se enraíza em uma estrutura relacional que pode ser observada a partir do próprio processo de construção espaço-território. A conflitualidade enraizada na historicidade das comunidades rurais negras, em sua ascendência africana, reflete-se em uma territorialidade de desafios de sustentabilidade e de possibilidade de reprodução e de fortalecimento étnico-cultural.

Verifica-se, então, um ciclo na reprodução de desigualdade dessas mulheres, engendrado por distintos eixos de opressão. As mulheres não possuem práticas de lazer e culturais- regionais ou de matrizes afro-brasileiras- condicionamento correspondente à ausência de políticas de fortalecimento e preservação étnico-racial das comunidades tradicionais negras, do conhecimento tradicional e informal transmitidos de forma geracional.

Há ainda um acesso assimétrico à saúde capaz de ser explicado à luz da abordagem dos determinantes sociais de desigualdade em saúde, demandando uma política de saúde intersetorial, transversal e focalizada para este grupo étnico. Com exceção do PBF, há a ausência dos programas do PBQ. Os dados demonstraram que não há o desenho de política educacional local para as mulheres do quilombo, cursos de aperfeiçoamento profissional, com a ausência de investimento e de capacitação no uso das tecnologias da informação e da comunicação.

Outra lacuna constatada na pesquisa e que pode impactar em um futuro próximo na própria significação dos matizes culturais desse povo são as políticas de incentivo às práticas tradicionais, como a cerâmica, realizada principalmente entre as mulheres mais maduras. Não se verificou no estudo essa atividade entre as mulheres mais jovens que recebem o PBF e que poderiam ser iniciadas no artesanato do barro. A comercialização da cerâmica demonstrou ser um importante acréscimo de rendimento, soma-se a esse fato a potencial possibilidade de contribuir para a autoestima e o empoderamento das mulheres.

A comunidade possui uma organização associativa cujas mulheres participam como ouvintes, com frequência de participação, sobretudo, mensal. As ações da Associação junto ao poder 
público ainda não lograram transformações positivas de cunho mais estrutural para os Negros do Riacho.

Diante dessas informações, verificam- se a ocorrência das observações de Souza e Araújo sobre a invisibilidade e as necessidades da mulher quilombola, características essas também encontradas na realidade das mulheres da terra de Trajano: "é dentro da frágil estrutura dessas comunidades que a mulher quilombola desempenha diversos papeis importantes para a sobrevivência de seu povo, de sua cultura e da própria subsistência dos seus descendentes" (SOUZA; ARAÚJO, 2010, p. 6).

\section{FINANCIAMENTO}

Esta pesquisa contou com o financiamento da bolsa PNPD/Capes e do Programa de Pósgraduação em Estudos Urbanos e Regionais (UFRN).

\section{REFERÊNCIAS}

ANDRADE FILHO, E.; GUEDES, C; CRUZ, M. S. F.; ARAÚJO, A. C. S. Breve diagnóstico situacional da Comunidade "Negros do Riacho". Currais Novos, 2011. Disponível em: http://epitacioandradefilho. blogspot.com.br/2012/06/negros-do-riacho.html. Acesso em: 30 set. 2015.

ARRUTI, J. M. Políticas públicas para quilombos: terra, saúde e educação. In: PAULA, M.; HERINGER, R. (Org.). Caminhos convergentes: Estado e sociedade na superação das desigualdades raciais no Brasil. Rio de Janeiro: Fundação Heinrich Boll/ActionAid, 2009. p. 75-110.

ASSUNÇÃO, L. C. Os negros do Riacho: estratégias de sobrevivência e identidade social. Natal: UFRN/ CCHLA, 1994.

ATO DAS DISPOSIÇÕES CONSTITUCIONAIS TRANSITÓRIOS. Brasília-DF,1988. Disponível em: http:// www2.camara.leg.br/legin/fed/conadc/1988/constituicao.adct-1988-5-outubro-1988-322234normaatualizada-pl.pdf. Acesso em: 12 set. 2015.

BEZERRA, A. S. As Associações Comunitárias de Quilombos: políticas públicas e participação política. In: CONGRESSO PORTUGUÊS DE SOCIOLOGIA 40 ANOS DE DEMOCRACIA(S):

PROGRESSOS, CONTRADIÇÕES E PROSPETIVAS, 8., 2014, Évora. Anais [...]. Disponível em: https:// associacaoportuguesasociologia.pt/viii_congresso/VIII_ACTAS/VIII_COM0386.pdf. Acesso em: 26 out. 2015.

BOURDIEU, P. Razões práticas: sobre a teoria da ação. Campinas, SP: Papirus, 1996.

BRASIL. Decreto n. 6.261, de 20 de novembro de 2007. Dispõe sobre a gestão integrada para o desenvolvimento da Agenda Social Quilombola no âmbito do Programa Brasil Quilombola, e dá outras providências. Disponível em: http://www.planalto.gov.br/ccivil_03/_Ato2007-2010/2007/Decreto/ D6261.htm. Acesso em: 12 set. 2014.

CARTILHA DOS POVOS E DAS COMUNIDADES TRADICIONAIS. Coordenadoria de Inclusão e Mobilização Sociais (CIMOS). Ministério Público de Minas Gerais, 2013. Disponível em: http://www. caa.org.br/media/publicacoes/PUBLICACAO_ESPECIAL_DIREITOS_DOS_POVOS_E_COMUNIDADES_ TRADICIONAIS_oibAP6o.pdf. Acesso em: 10 out. 2015.

CASHMORE, E. Dicionário de relações étnicas e raciais. São Paulo: Selo Negro/Summus, 2000. 
CHAGAS, M. A política do reconhecimento dos "remanescentes das comunidades dos quilombos". Horizontes Antropológicos, Porto Alegre, v. 7, n. 15, p. 209-35, 2001. Disponível em: http://www.scielo. br/pdf/ha/v7n15/v7n15a09.pdf. Acesso em: 14 dez. 2015.

COMMISSION ON SOCIAL DETERMINANTS OF HEALTH (CSDH). A Conceptual Framework for Action on the Social Determinants of Health. Discussion paper for the Commission on Social Determinants of Health. DRAFT, 2007. Disponível em: http://www.who.int/social_determinants/resources/csdh_ framework_action_05_07.pdf. Acesso em: 13 jul. 2012.

DIAS, Reinaldo. Introdução à Sociologia. 2. ed. São Paulo: Pearson, 2013.

FERNANDES, B. M. Sobre a tipologia de territórios. In: SAQUET, M. A.; SPOSITO, E. S. (Org.). Territórios e territorialidades: teorias, processos e conflitos. São Paulo: Expressão Popular/UNESP,2009. p. 197-216.

FIDELIS, L. M.; BERGAMASCO, S. M. P. Quilombos e a agroecologia: a agricultura tradicional como estratégia de resistência da comunidade quilombola João Surá. Revista Eletrônica da Associação dos Geógrafos Brasileiros, Três Lagoas, MS, n. 18, p. 112-41, nov. 2013. Disponível em: http://seer.ufms.br/ index.php/RevAGB/article/view/401. Acesso em: 20 nov. 2015.

FIGUEIREDO SANTOS, J. A. Classe social e desigualdade de saúde no Brasil. Revista Brasileira de Ciências Sociais, São Paulo, v. 26, n. 75, p. 27-55, 2011. Disponível em: http://www.scielo.br/scielo. php?script=sci_arttext\&pid=S0102-69092011000100002\&lng=pt\&nrm=iso. Acesso em: 12 jun. 2012.

GIDDENS, A. Sociologia. São Paulo: Artmed, 2005.

GUIA DO PROGRAMA BRASIL QUILOMBOLA. Secretaria de Políticas de Promoção da Igualdade Racial da Presidência da República. Brasília, 2013. Disponível em: http://www.seppir.gov.br/portal-antigo/ arquivos-pdf/guia-pbq. Acesso em: 13 out. 2016.

HERNÁNDEZ, C. O. Reconhecimento e autonomia: o impacto do Pronaf-Mulher para as mulheres agricultoras. In: PARRY, S.; CORDEIRO, R.; MENEZES, M. (Org.). Gênero e geração em contextos rurais. Florianópolis: Ed. Mulheres, 2010. p. 95-120. Disponível em: https://www.ufpe.br/ documents/1016303/1020379/genero+e+gera_o+em+contextos+rurais.pdf/171b01b8-2ded-48dc9639-8e7e34c7bbcc.

LEITE, I. B. Os quilombos no Brasil: questões conceituais e normativas. Etnográfica, Lisboa, v. 4, n. 2, p. 333-54, 2000. Disponível em: http://ceas.iscte.pt/etnografica/docs/vol_04/N2/Vol_iv_N2_333-354.pdf. Acesso em: 15 set. 2015.

LÉO NETO, N. A. Mulheres que ousam lutar: a construção da identidade como mulher quilombola. In: ENCONTRO DA REDE FEMINISTA DE ESTUDOS SOBRE A MULHER E RELAÇÕES DE GÊNERO, 17., 2012, João Pessoa, PB. Anais [...]. João Pessoa, PB, 2012. Disponível em: http://docplayer.com.br/51497061Mulheres-que-ousam-lutar-a-construcao-da-identidade-como-mulher-quilombola-1.html. Acesso em: 25 set. 2015.

LIMA, M. B. Identidade étnico/racial no Brasil: uma reflexão teórico-metodológica. Revista Fórum Identidades, ano 2, v. 3, p. 33-46, jan./jun. 2008. Disponível em: https://seer.ufs.br/index.php/ forumidentidades/article/view/1742/1533. Acesso em: 20 out. 2015.

LINK, B.; PHELAN, J. Social conditions as fundamental causes of disease. Journal of Health and Social Behavior. Extra Issue, p. 80-94, 1995. Disponível em: https://www.jstor.org/stable/pdf/2626958.pdf. Acesso em: 29 jun. 2018. 
MEDEIROS, R. M. V. Território, espaço de identidade. In: SAQUET, M. A.; SPOSITO, E. S. (Org.). Territórios e territorialidades: teorias, processos e conflitos. São Paulo: Expressão Popular/UNESP, 2008. p. 217-228.

MONTEIRO, K. S. As mulheres quilombolas na Paraíba: terra, trabalho e território. 2013. Dissertação (Mestrado em Geografia)- Universidade Federal da Paraíba, João Pessoa, 2013. Disponível em: http:// www.geociencias.ufpb.br/posgrad/dissertacoes/karoline_monteiro.pdf. Acesso em: 15 nov. 2015.

NEGREIROS, A. M. Negros do Riacho: quem é este povo? 2001. Monografia (Graduação em Comunicação Social) - Universidade Federal do Rio Grande do Norte, 2001.

O'DWYER, E. C. Terras de quilombo: identidade étnica e os caminhos do reconhecimento. TOMO, São Cristóvão, SE, n. 11, p. 43-58, jul./dez. 2007. Disponível em: https://seer.ufs.br/index.php/tomo/article/ download/446/363.

O'DWYER, E. C. Os quilombos e a prática profissional dos antropólogos. In: O'DWYER, E. C. (Org.). Quilombos: identidade étnica e territorialidade. Rio de Janeiro: Editora FGV, 2002. p. 13-42.

OLIVEIRA, B. J. C. Comunidade Negros do Riacho/RN: condições socioeconômicas e o avanço da anemia falciforme. 2012. Trabalho de Conclusão de Curso (Bacharelado em Serviço Social) - Universidade Federal do Rio Grande do Norte, Natal, 2012. Disponível em: https://monografias.ufrn.br/jspui/ handle/1/304. Acesso em: 10 set. 2015.

PARÉ, M. L.; OLIVEIRA, L. P.; VELLOSO, A. D’A. A educação para quilombolas: experiências de São Miguel dos Pretos em Restinga Seca (RS) e da Comunidade Kalunga do Engenho II (GO). Cadernos Cedes, Campinas, SP, v. 27, n. 72, p. 215-32, maio/ago. 2007. Disponível em: http://www.scielo.br/pdf/ccedes/ v27n72/a07v2772.pdf. Acesso em: 27 nov. 2015.

PROGRAMA BRASIL QUILOMBOLA. Monitoramento, 2016. Disponível em: http://monitoramento. seppir.gov.br/SEPPIR/PR. Acesso em: 5 jan. 2013.

POUTIGNAT, P.; STREIFF-FENART, J. Teorias da etnicidade. Seguido de grupos étnicos e suas fronteiras de Frederik Barth. São Paulo: UNESP, 1998.

RAFFESTIN, C. A produção das estruturas territoriais e sua representação. In: SAQUET, M. A.; SPOSITO, E. S. (Org.). Territórios e territorialidades: teorias, processos e conflitos. São Paulo: Expressão Popular/ UNESP, 2008. p. 17-36.

REMMERS, G. G. A agricultura tradicional y agricultura ecológica: vecinos distantes. Agricultura y Sociedad, n. 66, p. 201-20, enero/marzo 1993. Disponível em: https://dialnet.unirioja.es/servlet/articul o?codigo $=82907 \&$ orden $=106684 \&$ info=link. Acesso em: 20 set. 2015.

SCHMITT, A.; TURATTI, M. C. M.; CARVALHO, M. C. P. A atualização do conceito de quilombo: identidade e território nas definições teóricas. Ambiente \& Sociedade, Campinas, SP, n. 10, p. 12936, jan./jun. 2002. Disponível em: http://www.scielo.br/scielo.php?script=sci_arttext\&pid=S1414753×2002000100008. Acesso em: 15 set. 2015.

SCOTT, P.; RODRIGUES, A. C.; SARAIVA, J. C. Onde mal se ouvem os gritos de socorro: notas sobre a violência contra a mulher em contextos rural. In: PARRY, S.; CORDEIRO, R.; MENEZES, M. (Org.). Gênero e geração em contextos rurais. Florianópolis: Ed. Mulheres, 2010. p. 63-94.

SILVA, J. T. O riacho e as eras. Memória, identidade e território em uma comunidade rural negra no Seridó Potiguar. 2009. Dissertação (Mestrado em História Social) - Universidade Federal do Ceará, Fortaleza, 2009. Disponível em: www.repositorio.ufc.br/bitstream/riufc/2896/1/2009_dis_tsilva.pdf. Acesso em: 20 ago. 2018. 
SILVA, R. A.; MENEZES-SANTOS, J. A. Ser mulher nas comunidades quilombolas: vivências relacionadas à família e ao trabalho. In: SEMINÁRIO ENLAÇANDO SEXUALIDADES, 4., Salvador, 2015. Anais [...]. Salvador: UNEB, 2015. Disponível em: http://www.uneb.br/enlacandosexualidades/files/2015/07/Com unica\%C3\%A7\%C3\%A3oRoseaneAmorim.pdf. Acesso em: 20 jan. 2016.

SHIRAISHI NETO, J. Os quilombos como novos sujeitos de Direito: processo de reconhecimento e impasses. Cadernos UNDB: estudos jurídicos interdisciplinares, v. 04, p. 203-223, 2014. Disponível em: https://diamantina.cedeplar.ufmg.br/portal/download/diamantina-2016/259-440-1-

RV_2016_10_09_00_58_43_345.pdf. Acesso em: 26 out. 2019.

SOUZA, P. B.; ARAÚJO, K. A. A mulher quilombola: da invisibilidade à necessidade por novas perspectivas sociais e econômicas. In: ESTEVES, J. T.; ALBINO, J. L.; FALCÃO, P. R. L. (Org.). Direitos, gênero e movimentos sociais II. Florianópolis: CONPEDI, 2014. p.163-182. Disponível em: http:// publicadireito.com.br/publicacao/ufpb/livro.php?gt=234. Acesso em: 12 out. 2019.

SOUZA, B. O. Movimento Quilombola: reflexões sobre seus aspectos político-organizativos e identitários. In: REUNIÃO BRASILEIRA DE ANTROPOLOGIA, 26., jun. 2002, Porto Seguro, BA. Disponível em:

http://www.aba.abant.org.br/conteudo/ANAIS/CD_Virtual_26_RBA/grupos_de_trabalho/trabalhos/ GT\%2002/barbara\%20oliveira\%20souza.pdf. Acesso em: 10 dez. 2015.

SOUZA, C. L. F.; ANTUNES, L. B.; NUNES, H. L. Mulheres quilombolas e educação. Identidade!, São Leopoldo, RS, v. 18, n. 3, ed. esp., p. 382-6, dez. 2013. Disponível em: http://periodicos.est.edu.br/ index.php/identidade/article/viewFile/1186/1148. Acesso em: 27 nov. 2015.

WRIGHT, E. O. Logics of class analysis. In: CONLEY, D.; LAREAU, A. (Org.). Social class: how does it work? [S.I.]: Russell Sage Foundation, 2008. p. 329-49.

\section{Sobre os autores:}

Marcela Fernanda da Paz de Souza: Pós-doutora em Estudos Urbanos e Regionais (PNPD/CapesUFRN). Doutora em Ciências Sociais (UFJF). Doutorado sanduíche em Sociologia no Instituto de Ciências Sociais de Lisboa (PDSE/Capes). Bacharel em Comunicação Social (BIC-BCCG/UFJF). Professora do Curso de Comunicação Social - Jornalismo na Universidade Estadual de Minas Gerais- Unidade Administrativa Frutal. Consultora de Pesquisa e Metodologia e pesquisadora. E-mail: marceladapaz2015@gmail.com, Orcid: http://orcid.org/0000-0001-7437-5436

Wagner Luiz Alves da Silva: Mestre em Estudos Urbanos e Regionais; especialista em Gestão Ambiental Urbana; graduado em Geografia - bacharelado e licenciatura plena, pela Universidade Federal do Rio Grande do Norte (UFRN). Docente do Instituto Federal de Educação, Ciência e Tecnologia do Rio Grande do Norte. E-mail: wagner.alves@ifrn.edu.br, Orcid: http://orcid.org/0000-0002-8873-3991

Luzimar Pereira da Costa: Mestre em Desenvolvimento e Meio Ambiente pela Universidade Federal do Rio Grande do Norte (UFRN). Graduada nos cursos de Licenciatura Plena em Geografia pelo Instituto Federal de Educação, Ciências e Tecnologia do RN (IFRN) e Tecnologia em Meio Ambiente pelo Centro Federal de Educação Tecnológica do Rio Grande do Norte. Professora da Rede estadual de ensino da Secretaria de Estado da Educação do Rio Grande do Norte. E-mail: luzimarpereira@gmail.com, Orcid: http://orcid.org/0000-0003-1386-9314 
